(C) М.Ю. Киселев

\title{
ДОКЛАД И.С. ГУРВИЧА ПО ЭТНОГРАФИИ ЯКУТИИ В АРХИВЕ АКАДЕМИИ НАУК
}

\begin{abstract}
В статье представлена информация о хранящемся в Архиве Российской академии наук докладе И.С. Гурвича «Новые даннье об этнографии Северной Якутии», прочитанном на заседании сессии Института этнографии АН СССР 26 апреля 1955 г. В докладе приведены сведения об экспедициях Института языка, литературы и истории Якутского филиала АН СССР в 1953-1954 г2. по изучению состава населения, быта и культуры народов, проживавших в бассейнах рек Яны и Нижней Лень (Верхоянский, Усть-Янский, Беризинский, Жиганский районы) $)^{1}$. В результате широкого сплошного этнографического обследования удалось не только получить материал для составления этнографической карты северных районов Якутии, уточнить по ряду районов этническую статистику, но и выявить ареаль расселения отдельных этнических групп. Ученый собрал сведения для характеристики прочесса национальной консолидации, весьма интенсивно протекавшей на севере Якутии. Он отмечал, что на самом деле исторический прочесс на Севере шел и имел свои специифические особенности, и «дело советских историков и этнографов раскрыть сущность этих процессов, поскольку связанной истории народов Севера все еще нет».
\end{abstract}

Ключевые слова: Гурвич И.С., Якутия, этнография, история, архив, Российская академия наук

Архив Российской академии наук (АРАН) остается одним из старейших ведомственных архивохранилищ и информационным центром по истории науки. Среди документов архивных фондов академических учреждений сохранился фонд Института этнографии Академии наук СССР (ИЭ АН СССР), где многие годы работал известный этнограф и исследователь Якутии И.С. Гурвич. Большинство научных работ И.С. Гурвича опубликованы (Гурвич 1956, 1960, 1963, 1966, 1970, 1975, 1977), он являлся ответственным редактором ряда фундаментальных трудов института. В архивном фонде Института этнографии АН СССР отложилась стенограмма доклада И.С. Гурвича «Новые данные об этнографии Северной Якутии» на заседании сессии института 26 апреля 1955 г. (АРАН: 23-46). В докладе приведены сведения об экспедициях Института языка, литературы и истории Якутского филиала АН СССР в 1953-1954 гг. по изучению состава населения, быта и культуры народов, проживавших в бассейнах рек Яны и Нижней Лены (Верхоянский, Усть-Янский, Беризинский, Жиганский районы).

\footnotetext{
Киселев Михаил Юрьевич - руководитель центра учета и обеспечения сохранности документов, Архив Российской академии наук (117218 Москва, ул. Новочеремушкинская, 34). Эл. почта: kiss_ran@mail.ru. Kiselev, Mikhail Yu. - Archive of the Russian Academy of Sciences (Moscow, Russia). E-mail: kiss_ran@mail.ru

${ }^{1}$ В статье сохранена терминология источника (прим. ред.).
} 


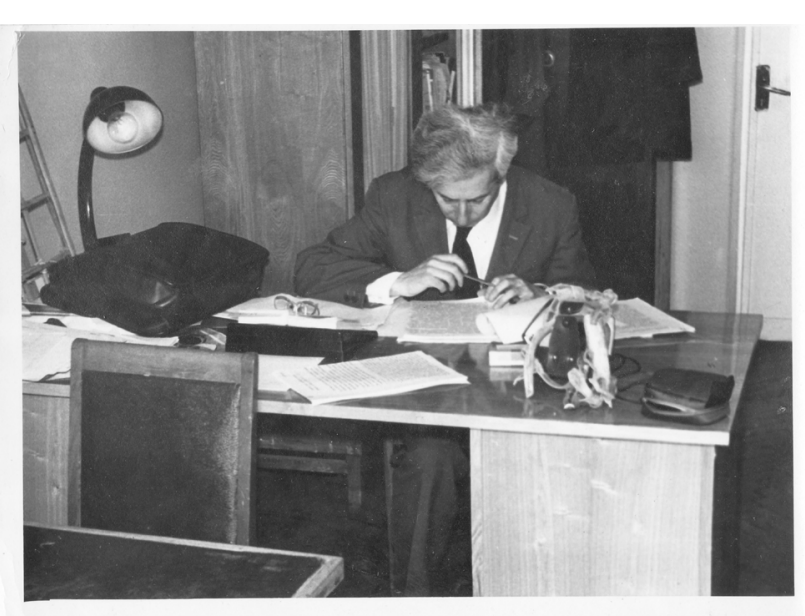

Рис. 1. И.С. Гурвич за работой (фото из архива семьи Гурвич, 2020).

В своем докладе И.С. Гурвич сообщал, что с 1951 г. Институт языка, литературы и истории Якутского филиала АН СССР начал сплошное этнографическое обследование северных районов Якутской АССР, которые отличались крайне сложным этническим составом. За годы после Октябрьской революции изменились быт, жизнь, расселение этнических групп народов Севера, описанных дореволюционными этнографами, но по их трудам, нередко устаревшим, и в середине 1950-х гг. нередко рисовали современное состояние северных народов. Подробно ученый остановился на материале, характеризующем процесс национальной консолидации, интенсивно протекавший на севере Якутии.

И.С. Гурвич отмечал, что процесс сближения между отдельными этническими группами значительно усилился после 1917 г., что прежде всего было связано с упразднением прежних архаических административных единиц. В результате обрусевшие юкагиры и чуванцы окончательно слились с русскими старожилами. Преодолению замкнутости отдельных этнических групп способствовало проводившееся первичное землеводоустройство и районирование. При проведении этих мероприятий охотничьи и рыболовецкие участки выделялись той или иной группе населения по хозяйственному принципу. В качестве примера ученый приводил районы бассейна реки Индигирки, где водились дикие олени и горные бараны, которые были закреплены за группами хозяйств, занимавшихся промысловой охотой на крупно-копытных. В эти районы р. Мома, Селленнях, Уянды, наиболее подходящих для промысла, стягивались хозяйства из различных ламутских родов и кочевые якуты-оленеводы.

При создании колхозов, переходе на устав сельскохозяйственной артели, товарищества объединялись, в результате этого в них сосредотачивались обычно люди из различных административных и этнических групп. Так на Колыме в колхоз Турваургин вошли чукчи, эвены, юкагиры, якуты. На реке Яне в колхоз им. Сталина вошли эвены Кунгурского, Момольского родов и якуты. Коллективизация перестроила хозяйства в тундре и привела к тому, что мелкие изолированные и обособленные этнические группы стали быстро сближаться. В низовьях рек Колымы и Индигирки, где в прошлом был целый ряд мелких замкнутых этнических групп, получило распространение такое явление, как многоязычие. Собранный И.С. Гурвичем материал показал, что нижне-колымские чукчи, эвены, одулы владели тремя-четырьмя языками - родным (своей группы) языком и языком своих соседей.

При этом выделялся ведущий язык: в низовьях реки Колымы им был русский язык, в низовьях рек Индигирки, Яны, Лены - якутский. В последней экспедиции ученый наблюдал в Саккырырском и Усть-Янском районах любопытное явление пе- 
рехода эвенов со своего родного языка на якутский. Он встречался с тем, как протекал разговор на двух языках: молодежь говорила на якутском языке, старики отвечали и подавали реплики на эвенском языке, причем молодежь лучше знала якутский язык, чем эвенский, и зачастую даже не говорила по-эвенски.

Ученый отмечал, что в прошлом у каждой этнической группы был свой выработанный в течение длительного времени уклад хозяйства. После коллективизации эти этнографические типы хозяйства перестали быть характерными для определенной этнической группы. На Индигирке и Колыме оленеводством чукотского типа занялись эвены, так как дикие олени исчезли. К оленеводству, промысловым хозяйствам перешли отдельные группы якутов. Унифицировались по Северу способы выпаса оленей, в известной степени единообразными стали нартовая упряжка, способы рыболовства и охоты.

И.С. Гурвич констатировал, что за последние десятилетия вместе с общей перестройкой быта отдельные этнические группы утеряли внешние культурные признаки, выделявшие их из среды окружающих народностей. Для эвенско-эвенкийского народного костюма характерным считался нагрудник и узкий, облегающий фракообразный покрой дохи. К середине 1950-х гг. почти все группы эвенов и эвенков севера Якутии не носили ни передников-нагрудников, ни доху, исключение составляли нижне-колымские эвены. Чукотский глухой мужской костюм, очень удобный и распространенный на Севере, стал характерным не только для чукчей, но также использовался на западе в тундре якутами, эвенами и русскими старожилами. То же самое ученый говорил о литературе и фольклоре: распространение и популярность по всему северу Якутии получали книги и произведения, которые не являлись достоянием какой-нибудь этнической группы.

Процесс сближения обособленных в прошлом этнических групп с якутами, основной народностью Якутской АССР, не во всех районах протекал одинаково. И.С. Гурвич отмечал, что процесс национальной консолидации в основном завершился в Олекском, Анабарском, Жиганском, Абыйском районах на западе реки Лены. Основное население этих районов - эвены и эвенки - еще в прошлом сблизилось с пришельцами якутами, которых было значительно больше, чем их, усвоило якутские язык и культуру, и, таким образом, образовались своеобразные культурные группы якутского народа. Однако на востоке реки Лены этот процесс не завершился полностью.

Отдельно ученый останавливался на процессе объединения мелких этнических групп в Усть-Янском районе. В прошлом там обитали следующие народности: эвены, хромы, ламунсинцы, юкагиры, омолойцы, якуты, тунгусы. Кроме того, здесь жили русские старожилы Устьянского крестьянского общества (семь хозяйств). Они в XIX в. перешли на якутский язык и не использовали русский язык. Таким образом, еще до советской власти происходило объединение отдельных этнических групп. Юкагиры сблизились с эвенами и перешли на эвенский язык, в дальнейшем низовские эвены и юкагиры в большинстве семей утратили эвенский язык и стали говорить по-якутски. По материальной культуре эти группы очень мало отличались друг от друга. Однако, в каждой из них у стариков сохранилось представление, что они были особым народом, то есть национальное самосознание не утратилось.

Аналогичное положение было в Булунском районе в низовьях реки Лены. Русские старожилы окончательно слились с якутами еще в XIX в., на востоке кочевали юкагиры и эвены, сохранявшие до недавнего времени свой эвенский язык. В этой группе, составлявшей 1/15 часть населения района, помнили о том, что они эвены. 
Более интересной, по мнению И.С. Гурвича, была группа эвенков - кюп-эжанцев. Когда-то в низовьях Яны были эжанский и кюпский роды эвенков, которые утеряли свой язык в XIX в. Оба рода объединились, и в рассматриваемый период отличались от эвенков только тем, что старики помнили, что они когда-то считались бродячими тунгусами и платили налог меньше, чем якуты. В тот период имелся Кюп-эжанский наслег, однако, ученый не смог установить, на каком языке там говорили.

И.С. Гурвич отмечал путаницу в определении этнических групп населения. В Булунском районе все население - и эвены, и якуты - были объявлены и числились эвенами и эвенками. Ученому удалось выяснить, что основанием для причисления якутского населения к эвенам послужило в 1930-х гг. то, что они занимались не скотоводством, а оленеводством. Это укрепилось в административной районной практике - население числилось эвенками, хотя сами люди этого не признали. Приезжая обычно на праздники, руководители района просили выступить местных якутов на родном языке, и очень удивлялись, что никто этого сделать не может.

И.С. Гурвич отмечал, что на местах не всегда понимали и отдавали себе отчет о происходивших этнических процессах, которые были прогрессивными. По его мнению, «задача местных организаций - не пытаться законсервировать, гальванизировать мелкие архаические этнические единицы, которые отчасти сохранили местные языки, но являются двуязычными, не устраивать для них школы на эвенском языке, а облегчить этот процесс, к которому стремится местное население, сблизиться с эвенкско-эвенкийским народом». В качестве примера ученый приводил факт указания руководства об открытии школы с преподаванием на эвенском языке. И.С. Гурвич установил, что население двуязычно, а дети знают якутский язык не хуже эвенского. Кроме того диалект, на котором говорили эвены, проживавшие в этом наслеге, отличался от диалектов, на которых созданы учебники. Таким образом, обучение на эвенском языке детей означало задерживание их культурного развития.

Ученый констатировал, что экспедиции 1951-1954 гг. показали процесс глубочайшей перестройки хозяйства, быта и культуры населения северных районов Якутии. Большинство северных колхозов практиковало комплексное промысловое хозяйство, основанное на развитии традиционных для севера отраслей производства (оленеводство, охота, рыболовство). Однако соотношение этих отраслей в комплексе и техника ведения хозяйства резко изменились. В большинстве тундровых и межтундровых колхозов развивалось оленеводство, не только транспортного направления, но и по производству мяса и выделки шкур. Охота на крупно-копытных отошла на второй план, главное же место заняла товарная пушная охота. Рыболовство приобрело промышленное направление только в устьях рек, в большинстве колхозов это была подсобная отрасль хозяйства. Оленеводство получило распространение в тех районах, где оно в прошлом было слабо развито - Абыйском, Верхоянском, Средне-Колымском - якутские колхозы занимались им как отраслью, помогающей развивать пушной промысел.

Ученый отмечал попытки организации летом в лесотундре звероводческих ферм по выращиванию черно-серебристой лисицы; а также развитие коневодства, хорошо зарекомендовавшего себя в сочетании с оленеводством, и свиноводства, последнее, правда, слабо себя оправдало. При освоении огромных промысловых участков охотники и оленеводы использовали переносные традиционные формы жилища - чумы и яранги; палатки в большинстве районов севера оказались непрактичными и были заменены более удобными чумами. Изменилась и обстановка в чумах: появились 
деревянные полы и двери, окна, железные печи, часы, постели с подзорами, швейные машины. Колхозами был поставлен вопрос о разработке типовых жилищ и их массовом производстве с возможностью доставки и сборки на месте.

По мнению ученого, изменился и характер расселения внутри районов: территориально распыленные в прошлом жители стянулись к крупным поселкам и населенным пунктам. В Булунском районе от колхоза до колхоза было 300 км, в настоящее время они объединились; в Жиганском районе было два колхоза, объединившие сразу три села - Тумасское, Батамасское и Юкагирское - в результате три колхоза разместились на площади 400 кв. км. На Севере население стало получать значительные денежные доходы, составлявшие 10-30 руб. на один трудодень. В то же время И.С. Гурвич наблюдал сохранившуюся традицию питания в Верхоянском районе, когда отсутствовал обед, а вечером употреблялось невероятное количество мяса, даже в интернатах. Население от 18 до 45 лет умело писать и читать, бригадиры, заведующие фермами, руководители колхозов имели образование в объеме 6-7 классов. В большинстве северных районов, как показали результаты экспедиций, специалисты со средним специальным образованием (радисты, киномеханики, ветеринарные техники, зоотехники, фельдшера, учителя) были коренными жителями районов.

И.С. Гурвич констатировал, что на Севере не стоял вопрос борьбы с шаманством, причем отход населения от шаманов и знахарей прошел значительно быстрее, чем на Кавказе и в Средней Азии. Он связывал этот факт с тем, что на Севере плотность населения значительно меньше, и традиции не так сохранялись, как в местах большой плотности этнических групп. В экспедициях тщательно фиксировался этнографический материал, воспоминания людей, помнящих приемы охоты с луком и стрелами, массовые поколки оленей на переправах, видевших и исполнявших шаманские мистерии, знакомых с охотничьими обрядами. Обследование каждой этнической группы сопровождалось сбором материалов, раскрывающих ее происхождение и историю. По мнению ученого, «эта работа проводилась не только потому, что современные этнические процессы невозможно понять, если не разобраться в прошлом каждой этнической группы, но и в связи с тем, что история народов Севера все еще запущенный участок».

В русской реакционной литературе прошлого, и, в особенности, за рубежом, утверждали, что истории у народов Севера не существовало, как не было войн и общественных движений, да и сами народы Севера были неспособны к историческому развитию. Полевой материал, данные о родоплеменном составе, описания материальной культуры, легенд и преданий в сочетании с архивными источниками позволили к середине 1950-х гг. внести некоторые коррективы в представления об истории Севера после присоединения Якутии к России.

И.С Гурвич констатировал, что удалось установить пути распространения якутской кочевой культуры: на протяжении XVII-XIX вв. районы скотоводства постепенно расширялись. Во второй половине XVII в. скотоводство интенсивно продвигалось в бассейн реки Вилюй, перед приходом русских людей оно проникло на берега реки Яны. Отсюда, отчасти из центра Якутии в XVIII-XIX вв. группы скотоводов продвинулись в бассейны рек Индигирки и Колымы. Удалось установить, что первоначально этот район был освоен коневодами. Затем, постепенно с обследованием новых территорий, с выжиганием тальника и леса, спуском озер, эти места были приспособлены под скотоводство. За 300 лет ландшафт Якутии был значительно изменен коренным населением - этот факт в литературе не был достаточно отмечен. 
Ученому, как участнику экспедиций, удалось проследить и пути формирования отдельных локальных групп якутского народа - вилюйской, колымской, индигирской. Согласно историческим источникам, данным о родоплеменном составе и историческим преданиям, эти группы сложились из отдельных частей родов центральных якутов. Интересным, по мнению И.С. Гурвича, являлся процесс образования своеобразных групп якутов-оленеводов в бассейнах рек Нижней Яны и Нижней Лены. Крайне немногочисленное эвенкийское и эвенское население было поглощено переселившимися сюда якутами. Якуты-переселенцы заимствовали у коренных жителей хозяйственный строй, коренное же население у них культуру: в результате образовалась своеобразная группа якутского народа.

Ученый подметил, что совсем не освещен в литературе вопрос изучения миграций эвенских и эвенкийских племен в XVII-XIX вв. Исследование показало, что в тот период продолжалось продвижение эвенков (после прихода русских) на север, и в результате отдельные юкагирские группы ассимилировались эвенками. Это привело к тому, что к середине 1950-х гг. почти все группы юкагиров утратили свой язык. По словам ученого, в экспедициях были получены интересные данные о миграции эвенков на восток, о том, что Ветельский род перекочевал сначала в бассейн реки Лены, потом в бассейн реки Колымы, и здесь растворился среди якутов.

В результате широкого сплошного этнографического обследования удалось не только собрать материал для составления этнографической карты северных районов Якутии, уточнить по ряду районов этническую статистику, но и выявить ареалы расселения отдельных этнических групп. Ученый писал, что на самом деле исторический процесс на Севере шел и имел свои специфические особенности, и «дело советских историков и этнографов раскрыть сущность этих процессов, поскольку связанной истории народов Севера все еще нет».

Представленная информация показывает высокий профессионализм И.С. Гурвича в вопросах этнографии, его усердие и заинтересованность в освещении быта и культуры этнических групп Якутии, любовь к народам и природе Севера. Материалы доклада позволяют расширить источниковедческую базу по научному наследию ученого и истории этнографии народов Севера России, могут быть использованы в исследовательских и образовательных целях.

\section{Источники}

АРАН - Новые данные об этнографии Северной Якутии // АРАН. Ф. 142. Оп. 1. Д. 652. Л. 23-46.

\section{Научная литература}

Гурвич И.С., Токарев С.А. Якуты // Народы Сибири / Под ред. М.Г. Левина, Л.П. Потапова. М.; Л.: Изд-во Акад. наук СССР, 1956. С. 267-328.

Гурвич И.С., Степанова М.В. Юкагиры // Народы Сибири / Под ред. М.Г. Левина, Л.П. Потапова. М.; Л.: Изд-во Акад. наук СССР, 1956. С. 885-895.

Гурвич И.С. Корякский национальный округ: (Очерки географии, истории, этнографии, экономики) / И.С. Гурвич, К.Г. Кузаков. М.: Изд-во Акад. наук СССР, 1960. 303 с.

Гурвич И.С. Русские старожилы долины реки Камчатки // Советская этнография. 1963. № 3. C. $31-41$.

Гурвич И.С. Русские на Северо-Востоке Сибири в XVII в. // Труды Института этнографии. Научный сборник. Т. 85. М.: Наука, 1963. С. 71-91. 
Гурвич И.С. Этническая история Северо-Востока Сибири // Труды Института этнографии. Научный сборник. Т. 89. М: Наука, 1966. 269 с.

Гурвич И.С. Алеуты Командорских островов (историко-этнографический очерк) // Советская этнография. 1970. № 5. С. 112-123.

Гурвич И.С. Юкагирская проблема в свете этнографических данных // Юкагиры. Историко-этнографический очерк. Новосибирск, 1975. С. 12-83.

Гурвич И.С. Юкагиры в советское время // Юкагиры. Историко-этнографический очерк. Новосибирск, 1975. С. 135-153.

Гурвич И.С. Этногенез и этническая история народов Севера. М.: Наука, 1975. 264 с.

Гурвич И.С. Культура северных якутов - оленеводов: К вопросу о поздних этапах формирования якутского народа. М.: Наука, 1977. 247 с.

\section{References}

Gurvich, I.S., and S.A. Tokarev. 1956a. Yakuty [Yakuts]. In Narody Sibiri [Peoples of Siberia], 267-328Moscow; Leningrad.

Gurvich, I.S., and M.V. Stepanova. 1956b. Yukagiry [Yukagirs]. In Narody Sibiri [Peoples of Siberia], 885-895. Moscow; Leningrad.

Gurvich, I.S. 1960. Koryakskiy natsional'nyy okrug: (Ocherki geografi, istorii, etnografii, ekonomiki) [Koryak National District: (Essays on Geography, History, Ethnography, Economics)] Moscow: Publishing house of Acad. Sciences of the USSR.

Gurvich, I.S. 1963. Russkiye starozhily doliny reki Kamchatki [Russian old-timers of the Kamchatka river valley]. Soviet ethnography 3: 31-41.

Gurvich, I.S.1963. Russkiye na Severo-Vostoke Sibiri v XVII v. [Russians in the North-East of Siberia in the 17th century]. Proceedings of the Institute of Ethnography. Scientific collection 85, 71-91. Moscow: Nauka.

Gurvich, I.S. 1966. Etnicheskaya istoriya Severo-Vostoka Sibiri [Ethnic history of the North-East of Siberia]. Proceedings of the Institute of Ethnography. Scientific collection 89, Moscow.

Gurvich, I.S. 1970. Aleuty Komandorskikh ostrovov (istoriko-etnograficheskiy ocherk) [Aleuts of the Commander Islands (historical and ethnographic essay)]. Soviet ethnography 5: 112-123.

Gurvich, I.S. 1975a. Yukagirskaya problema v svete etnograficheskikh dannykh [The Yukagir problem in the light of ethnographic data]. In Yukagiry. Istoriko-etnograficheskiy ocherk [Yukagir. Historical and ethnographic essay], 12-83. Novosibirsk.

Gurvich, I.S. 1975b. Yukagiry v sovetskoye vremya [Yukagirs in Soviet times] In Yukagiry. Istoriko-etnograficheskiy ocherk [Yukagir. Historical and ethnographic essay], 135-153. Novosibirsk. Gurvich, I.S. 1975. Etnogenez i etnicheskaya istoriya narodov Severa [Ethnogenesis and ethnic history of the peoples of the North]. Moscow: Nauka.

Gurvich, I.S. 1977. Kul'tura severnykh yakutov - olenevodov: K voprosu o pozdnikh etapakh formirovaniya yakutskogo naroda [The culture of the northern Yakuts - reindeer herders: On the issue of the late stages of the formation of the Yakut people]. Moscow: Nauka.

Kiselev, Mikhail Yu.

\section{A Report by I.S. Gurvich on the Ethnography of Yakutia (from the Archive of the Russian Academy of Sciences)}

The article provides information on the report by I.S. Gurvich "New Data on Ethnography of Northern Yakutia", stored in the Archive of the Russian Academy of Sciences, presented at a meeting of the Institute of Ethnography of the USSR Academy of Sciences on April 26, 1955. The report contains information about expeditions of the Institute of Language, Literature and History of the Yakut Branch of the USSR Academy of Sciences in 1953-1954. The expeditions aimed to study the composition of the population, life and culture of the peoples living in the 
basins of the Yana and Lower Lena rivers (Verkhoyansk, Ust-Yansky, Berizinsky, Zhigansky regions). As a result of a wide continuous ethnographic survey, it was possible not only to collect material for an ethnographic map of the northern regions of Yakutia and to further elaborate ethnic statistics for a number of regions, but also to identify areas of settlement of specific ethnic groups. The scientist managed to collect sufficient material to characterize the process of national consolidation, which was extremely intensive in the north of Yakutia. He noted that in reality the historical process in the North was still going on and had its own specificity, and "the task of Soviet historians and ethnographers is to reveal the essence of these processes, since there is still no connected history of the peoples of the North".

Keywords: Gurvich I.S., Yakutia, ethnography, history, archive, Russian Academy of Science 